\title{
Applicability of the Modified Ritchie-Knott-Rice Failure Criterion to Examine the Feasibility of Miniaturized Charpy Type SE(B) Specimens
}

\author{
Toshiyuki Meshii, ${ }^{1}$ Teruhiro Yamaguchi, ${ }^{2}$ and Yuma Higashino ${ }^{2}$ \\ ${ }^{1}$ Faculty of Engineering, University of Fukui, 3-9-1 Bunkyo, Fukui, Fukui, Japan \\ ${ }^{2}$ Graduate School of Engineering, University of Fukui, 3-9-1 Bunkyo, Fukui, Fukui, Japan \\ Correspondence should be addressed to Toshiyuki Meshii; meshii@u-fukui.ac.jp
}

Received 30 March 2016; Revised 30 August 2016; Accepted 8 September 2016

Academic Editor: Akihiko Kimura

Copyright ( $(2016$ Toshiyuki Meshii et al. This is an open access article distributed under the Creative Commons Attribution License, which permits unrestricted use, distribution, and reproduction in any medium, provided the original work is properly cited.

\begin{abstract}
This paper examined whether the modified Ritchie-Knott-Rice (RKR) failure criterion can be applied to examine the feasibility of miniaturized Charpy type $\mathrm{SE}(\mathrm{B})$ specimens of thickness-to-width ratio $B / W=1$. The modified RKR failure criterion considered in this paper is the $\left(4 \delta_{t}, \sigma_{22 c}\right)$ criterion which predicts the onset of cleavage fracture when the midplane crack-opening stress measured at a distance equal to four times the crack-tip opening displacement, denoted as $\sigma_{22 d}$, exceeds a critical stress $\sigma_{22 c}$. Specimens with $B$ values of $25,10,3$, and $2 \mathrm{~mm}$ (denoted as $25 \mathrm{t}, 10 \mathrm{t}, 3 \mathrm{t}$, and $2 \mathrm{t}$ specimens, resp.) manufactured with $0.55 \%$ carbon steel were tested at $20^{\circ} \mathrm{C}$. The results showed that the modified RKR criterion could appropriately predict the occurrence of cleavage fracture accompanied by negligibly small stable crack extension (denoted as $K_{J_{c}}$ fracture) naturally for the $25 \mathrm{t}$ and $10 \mathrm{t}$ specimens. The modified RKR criterion could also predict that $K_{I_{c}}$ fracture does not occur for the $2 \mathrm{t}$ specimen. The $\sigma_{22 c}$ obtained from specimens for the $25 \mathrm{t}$ and $10 \mathrm{t}$ specimens exhibited only a small difference, indicating that the $J_{c}$ obtained from the $10 \mathrm{t}$ specimens can be used to predict the $J_{c}$ that will be obtained with the $25 \mathrm{t}$ specimens.
\end{abstract}

\section{Introduction}

Test specimen size effects on the cleavage fracture toughness $J_{c}$ of a material in the ductile-to-brittle transition temperature (DBTT) region are important when assessing aging steel structures and reactor pressure vessels. Large scatter in $J_{c}$ has also been identified. A practical way to maintain conservatism in $J_{c}$ used in a structural integrity assessment is to specify the test specimen type and thickness, as found in the IAEA recommendations for monitoring the degradation of irradiated nuclear reactor pressure vessels (RPVs) [1]. To understand and become able to convert $J_{c}$ obtained with different specimen types and thicknesses, many studies have been performed in the past [2-10]. The cause of the test specimen size effect on $J_{c}$ has usually been categorized into the planar size effect on $J_{c}$ (i.e., different planar specimen configurations, including crack depth) and the test specimen thickness (TST) effect on $J_{c}$. The former has been assumed to result from constraint loss, and the latter results from statistical weakest link (SWL) size effects [2]. Here, this constraint loss is the loss in one-to-one correspondence between $J$ and the crack-opening stress $\sigma_{22}$ distribution (hereinafter denoted as J's inability to characterize the cracktip stress). Anderson et al. [5] gave theoretical background to the empirical TST effect on $J_{c}$, described as $J_{c} \propto(\text { TST })^{-1 / 2}$, by assuming the SWL model. However, the fact that $J_{c}$ has a nonnegligible lower bound value for large TST seemed to indicate that assuming the TST effect on the $J_{c}$ effect is thoroughly due to the SWL size effect not being perfect.

Thus, the authors have been working to explain the TST effect on $J_{c}$ based on $J$ 's inability to characterize the cracktip stress field [11-18]. The first work was to analyze and test whether there is "out-of-plane" stress $\sigma_{33}$ difference between $\mathrm{SE}(\mathrm{B})$ specimens with identical planar specimen configuration but with different thicknesses (hereinafter denoted as nonproportional specimens) [11]. This was because the 
formerly mentioned theoretical work of Anderson et al. implicitly assumed the nonproportional specimens. SE(B) specimens of width $W=25 \mathrm{~mm}$ and four thickness-to-width ratios $B / W$ of $0.25,0.5,1$, and 1.5 were considered. Fracture toughness tests results using $0.55 \% \mathrm{C}$ steel JIS S55C showed that the empirical relationship $J_{c} \propto B^{-1 / 2}$ holds for $B / W$ $=0.25 \sim 1$ and that $J_{c}$ is bounded for $B / W=1$ and 1.5. The difference in $J_{c}$, especially the bounding nature for large TST, clearly correlated with the difference in $\sigma_{33}$ at the fracture load. The idea to explain the TST effect by using the difference in $\sigma_{33}$ was supported by many researchers, such as [19-25].

Our second work was to become able to transfer $J_{c}$ 's between different TSTs. According to Chen et al. “... it is necessary to distinguish the concepts of the minimum toughness or the lower boundary of toughness values from that of the scatter band of toughness. The former is a definite parameter determined by the specimen geometry and yielding properties, and the latter is statistical behavior determined by the distribution of the weakest constituent" [26]; it was thought that the minimum toughness of a material, observed for a specific specimen and temperature, can be transferred by running an elastic-plastic finite element analysis (EP-FEA) with a given stress-strain relationship and a failure criterion. For this failure criterion, one of the modified Ritchie-Knott-Rice failure criterion, that is, the $\left(4 \delta_{t}, \sigma_{22 c}\right)$ criterion [3], which predicts the onset of cleavage fracture when the crack-opening stress $\sigma_{22}$, measured at a distance from the crack-tip equal to four times the cracktip opening displacement (CTOD) $\delta_{t}$ (hereinafter denoted as $\sigma_{22 d}$ ), exceeds a critical value $\sigma_{22 c}$ (Figure 1 ), was considered. The criterion successfully explained the TST effect on $J_{c}$ observed for S55C steel nonproportional SE(B) specimens $[13,17]$ and RPV ASTM A533 Grade B class 1 steel (A533B) proportional $\mathrm{SE}(\mathrm{B})$ specimens (whose $B / W$ ratio is held constant, though $B$ is changed) [18]. The tests were conducted in the DBTT region. The specimen thickness ranged from 6.25 to $37.5 \mathrm{~mm}$ for S55C steel and from 8 to $254 \mathrm{~mm}$ for A533B steel. Although the $J_{c}$ for the specimens exhibited a variation of 30.5 to $198 \mathrm{~N} / \mathrm{mm}$ for S55C steel and 7 to $106 \mathrm{~N} / \mathrm{mm}$ for $\mathrm{A} 533 \mathrm{~B}$ steel, the critical values for $\sigma_{22 c}$ exhibited variations of only $5 \%$ and $4 \%$, respectively. Another finding was that the stress level of $\sigma_{22 d}$ is maintained as $\sigma_{22 c}$ for increasing load. This finding suggested that the minimum $J$ that satisfied $\sigma_{22 d}=\sigma_{22 c}$ corresponds to the minimum $J_{c}$ for a specific specimen [18], which seemed to be consistent with the formerly mentioned opinion of Chen et al. [26].

This paper is an extension of our previous works to examine whether the $\left(4 \delta_{t}, \sigma_{22 c}\right)$ failure criterion can be applied to examine the feasibility of miniaturized Charpy type SE(B) specimens, that is, (1) whether the criterion could predict the occurrence of cleavage fracture accompanied by negligibly small stable crack extension (hereinafter denoted as $K_{J_{c}}$ fracture) and (2) whether $\sigma_{22 c}$ is identical to that observed in full sized specimens in the case where $K_{J_{c}}$ fracture occurred. $\mathrm{SE}(\mathrm{B})$ specimens of $B / W=1$ (Charpy type) with $B$ of 25 (full size), 10, 3, and 2 (miniaturized sizes) $\mathrm{mm}$ were examined (hereinafter denoted as $25 t, 10 t, 3 t$, and $2 t$ specimens, resp.). Additionally, 0.55\% carbon steel JIS S55C at

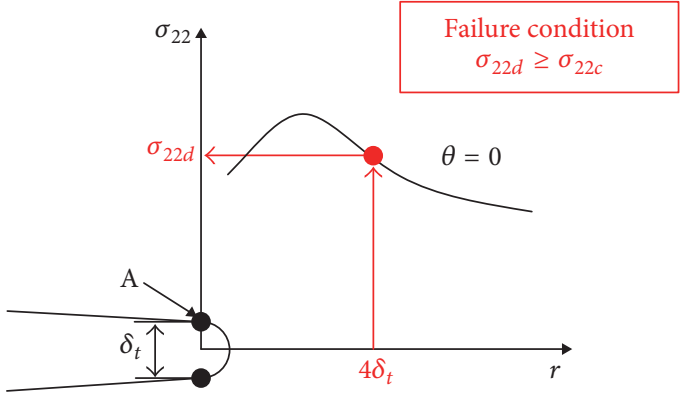

FIgURE 1: $\left(4 \delta_{t}, \sigma_{22 c}\right)$ failure criterion, which predicts the onset of cleavage fracture when the crack-opening stress $\sigma_{22}$, measured at a distance from the crack-tip equal to four times the crack-tip opening displacement (CTOD) $\delta_{t}$ (hereinafter denoted as $\sigma_{22 d}$ ), exceeds a critical value $\sigma_{22 c}[3,13]$.

$20^{\circ} \mathrm{C}$, which is in the DBTT region, was selected for material and test temperature. The results showed that the $\left(4 \delta_{t}, \sigma_{22 c}\right)$ criterion could appropriately predict a $K_{J_{c}}$ fracture naturally for the $25 \mathrm{t}$ and $10 \mathrm{t}$ specimens. The $\left(4 \delta_{t}, \sigma_{22 c}\right)$ criterion could also predict that $K_{J_{c}}$ fracture does not occur for the $2 \mathrm{t}$ specimen. The $\sigma_{22 c}$ obtained from specimens for the $25 \mathrm{t}$ and $10 t$ specimens exhibited only a small difference, indicating that the $J_{c}$ obtained from the 10t specimens can be used to predict the $J_{c}$ that will be obtained with the $25 \mathrm{t}$ specimens.

\section{Outline of This Work and Material Selection}

The outline of this work is summarized in Figure 2. First, fracture toughness tests with the $25 \mathrm{t}$ specimens were conducted and fracture toughness $J_{c}$ for this size was obtained. The critical stress $\sigma_{22 c}$ was obtained by running EP-FEA. Then, EP-FEA for miniaturized-size specimens of $10 \mathrm{t}, 3 \mathrm{t}$, and $2 \mathrm{t}$ were run, and the $\left(4 \delta_{t}, \sigma_{22 c}\right)$ failure criterion was applied to predict whether these specimens will experience $K_{J_{c}}$ fracture. For specimens for which $K_{J_{c}}$ fracture was expected, $J_{c}$ was predicted from the $\sigma_{22 c}$ of the $25 \mathrm{t}$ specimen. Finally, fracture toughness tests were conducted to confirm the predictions.

Considering that the nominal tensile strength $\sigma_{\mathrm{B} 0}$ to the nominal yield stress $\sigma_{\mathrm{YS} 0}$ ratio $\sigma_{\mathrm{B} 0} / \sigma_{\mathrm{YS} 0}$ for EURO RPVs and Japanese RPVs is equal to $1.3,0.55 \%$ C steel JIS S55C, whose room temperature $\sigma_{\mathrm{B} 0} / \sigma_{\mathrm{YS} 0}$ is known to show a higher value of 1.8 was selected for examination and tested at $20^{\circ} \mathrm{C}$. The material was quenched at $850^{\circ} \mathrm{C}$ and tempered at $650^{\circ} \mathrm{C}$. Chemical contents were C: $0.55 \%, \mathrm{Si}: 0.17 \%, \mathrm{Mn}: 0.61 \%, \mathrm{P}$ : $0.015 \%$, S: $0.004 \%$, Cu: $0.13 \%$, Ni: $0.07 \%$, and Cr: $0.08 \%$, respectively. Charpy impact test results and a true stresstrue strain curve are shown in Figure 3. These tests were conducted in accordance with JIS Z2242 [27] and Z2241 [28], respectively. Averaged nominal tensile properties were yield strength $\sigma_{\mathrm{YS} 0}=394 \mathrm{MPa}$, tensile strength $\sigma_{\mathrm{B} 0}=707 \mathrm{MPa}$, and elongation of $23.7 \%$.

\section{Fracture Toughness Tests and EP-FEA for 25t SE(B) Specimen to Obtain the Critical Stress $\sigma_{22 c}$ of $\left(4 \delta_{t}, \sigma_{22 c}\right)$ Failure Criterion}

3.1. Fracture Toughness Tests for $25 t$ SE(B) Specimen. The fracture toughness tests for the 25t $\mathrm{SE}(\mathrm{B})$ specimen were 


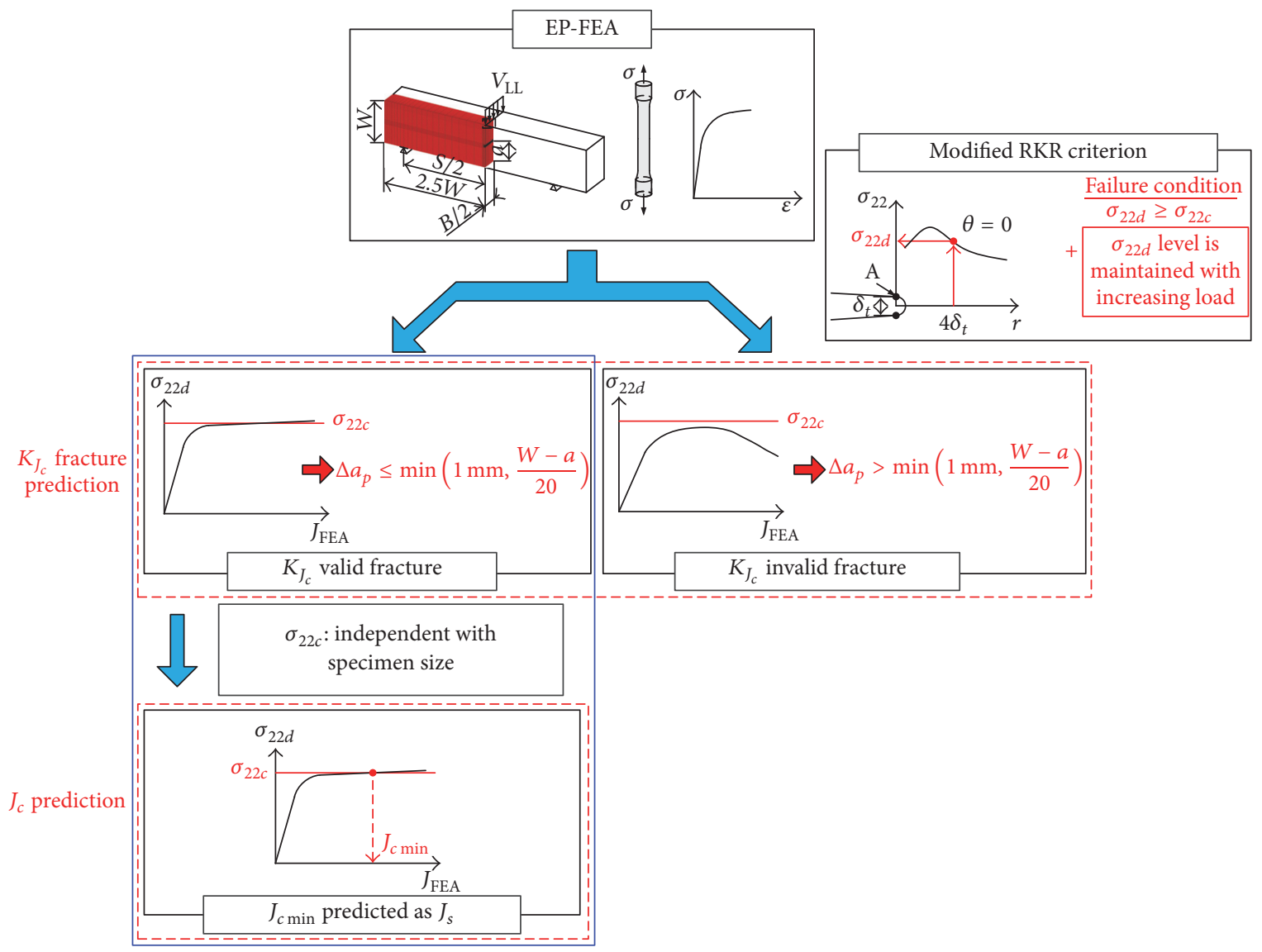

FIGURE 2: Prediction of $J_{c}$ for the miniature specimens from the experiment using full-size specimens.

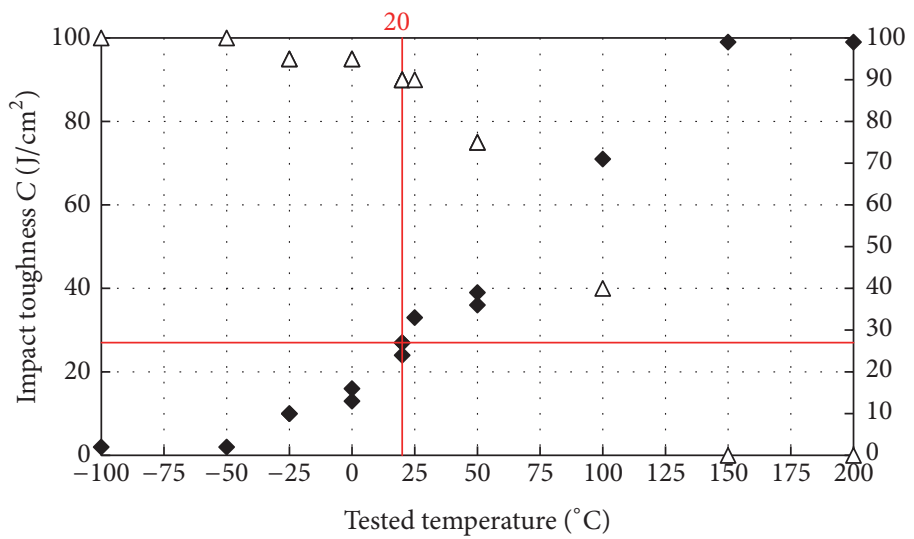

Impact toughness

$\triangle$ Brittle fracture (\%)

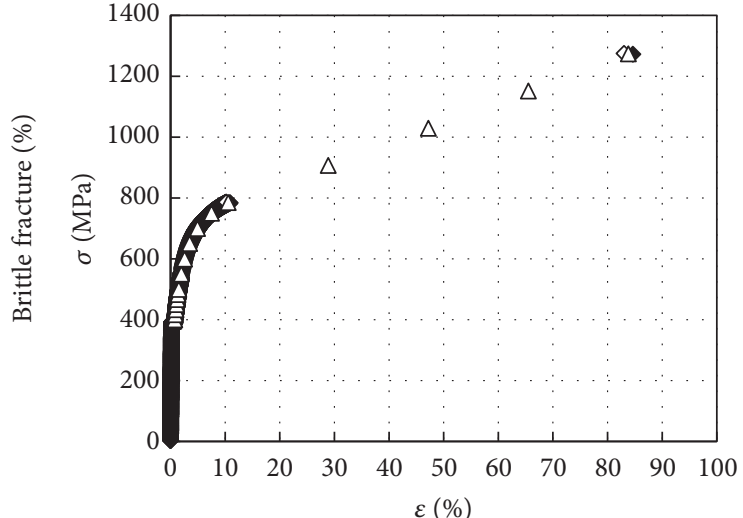

Tensile test number of $1 \quad \triangle$ FEA input Tensile test number of 2

(b)

FIGURE 3: Charpy impact test results and true stress-true strain curves of JIS S55C steel $\left(20^{\circ} \mathrm{C}\right)$.

conducted in accordance with ASTM E1921 [29]. The dimensions of the $\mathrm{SE}$ (B) specimen are shown in Figure 4. The length $L$ and the support span $S$ of the specimen were designed to satisfy $L / W \geq 4.5$ and $S / W=4.0$ and were fabricated as $L / W=4.52$ and $S / W=4.0$, where width $W=25 \mathrm{~mm}$.
Fatigue precrack was inserted using loads corresponding to $K_{\max }=22$ and $19 \mathrm{MPam}^{1 / 2}$ for the 1 st and final stages, respectively, which satisfied the requirement from the standard of $K_{\max } \leq 25$ and $20 \mathrm{MPam}^{1 / 2}$. For each discrete step, the reduction in $P_{\max }$ for any of these steps was $15 \%$, 

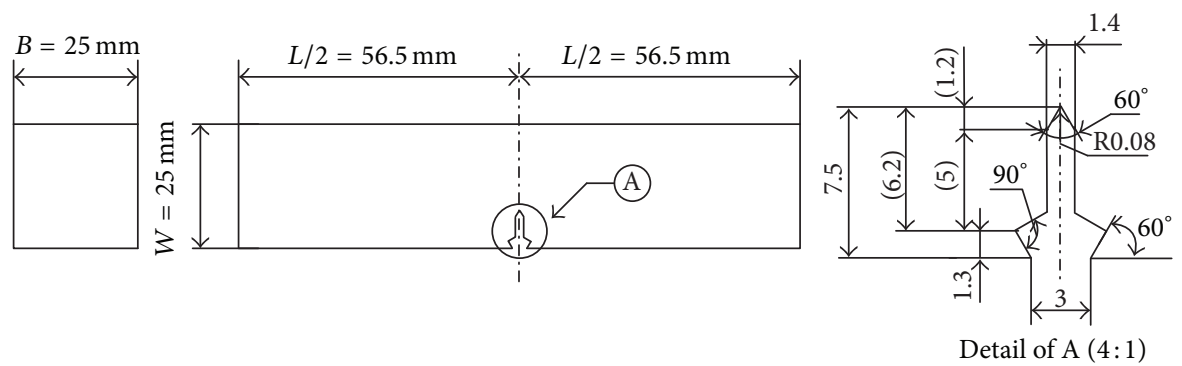

Figure 4: Dimensions of the 25t SE(B) specimen.

TABLE 1: Fracture toughness test results of S55C steel with 25t SE(B) specimen tested at $20^{\circ} \mathrm{C}$. Here, $\mu$ and $\Sigma$ in the table denote the mean and standard deviation of each parameter.

\begin{tabular}{lccccccccc}
\hline Specimen id & 1 & 2 & 3 & 4 & 5 & 6 & $\mu$ & $\Sigma$ & $2 \Sigma / \mu \%$ \\
\hline$a / W$ & 0.50 & 0.50 & 0.50 & 0.50 & 0.49 & 0.50 & 0.50 & 0.00 \\
$P_{c}(\mathrm{kN})$ & 23.1 & 22.7 & 22.4 & 24.1 & 23.6 & 22.4 & 23.1 & 0.629 \\
$K_{c}\left(\mathrm{MPam}^{1 / 2}\right)$ & 62.7 & 60.5 & 59.8 & 65.4 & 61.8 & 59.6 & 61.6 & 2.01 & \\
$J_{c}\left(\mathrm{~N} / \mathrm{mm}^{2}\right.$ & 46.8 & 35.9 & 33.5 & 61.1 & 52.0 & 37.8 & 44.5 & 9.81 & 10.9 \\
$K_{J_{c}}\left(\mathrm{MPam}^{1 / 2}\right)$ & 103 & 90.1 & 87.1 & 118 & 108 & 92.4 & 99.8 & 21.8 \\
$M$ & 105 & 137 & 147 & 80.6 & 96.6 & 130 & 116 & 23.7 \\
\hline
\end{tabular}

which satisfied the suggestion from the standard that the reduction in $P_{\max }$ for any of these steps be no greater than $20 \%$. A maximum force $P_{\max }$ and a minimum force $P_{\min }$ with a ratio of $R=P_{\min } / P_{\max }=0.1$ were applied at a loading frequency of $10 \mathrm{~Hz}$.

During the fracture toughness test, the loading rate was controlled to be in a specified range from 0.1 to $2.0 \mathrm{MPam}^{1 / 2} / \mathrm{s}$ to comply with the standard, resulting in a range from 1.21 to $1.71 \mathrm{MPam}^{1 / 2} / \mathrm{s}$. Test temperature requirements are to hold the temperature constant at $20 \pm 3^{\circ} \mathrm{C}$ for longer than $30 \mathrm{~B} / 25$ minutes, where the specimen thickness $B$ is $25 \mathrm{~mm}$, resulting in $20 \pm 1^{\circ} \mathrm{C}$ for 45 minutes. Six test results satisfying the ASTM E1921 requirements were considered for examination. The results clearly showed $K_{J_{c}}$ fracture.

Fracture toughness data are summarized in Table 1. The variable $K_{c}$ in the table is the stress intensity factor calculated from the fracture load $P_{c}$ and the measured crack depth-towidth ratio $a / W . K_{J_{c}}$ in the table is the fracture toughness in terms of stress intensity factor, calculated as $K_{J_{c}}=$ $\left[J_{c} E /\left(1-v^{2}\right)\right]^{1 / 2}$, where $E=206 \mathrm{GPa}$ is Young's modulus and $\nu=0.3$ is Poisson's ratio used for this conversion. $\mu$ and $\Sigma$ in the table denote the mean and standard deviation of each parameter. $M=(W-a) \sigma_{\mathrm{YSO}} / J_{c} \geq 30$ is a requirement of the standard placed on the ligament size, where $a$ is the crack length. Although not listed, negligible stable crack extension was measured using SEM observations.

In Table 1 , the standard deviation $\Sigma$ of $a / W$ was 0.00 , meaning that the potential $J_{c}$ scatter due to crack depth difference was minimized. The mean $\mu$ of $K_{J_{c}}$ was $99.8 \mathrm{MPam}^{1 / 2}$. Therefore, the master curve reference temperature $T_{0}$ in ASTM E1921 was approximately equal to the test temperature of $20^{\circ} \mathrm{C}$. The standard deviation to average ratio of $2 \Sigma / \mu=$ $21.8 \%$ for these data was sufficiently small compared with the ASTM E1921 prediction of $2 \Sigma / \mu=56(1-20 / \mu) \%=45 \%$.
The minimum $M$ was 80.6 , which satisfied the ASTM E1921 requirement of $M \geq 30$.

3.2. EP-FEA for $25 t S E(B)$ Specimen. The FE model used for the elastic-plastic analysis of the $\mathrm{SE}(\mathrm{B})$ specimen is shown in Figure 5. In this study, the FE models were fundamentally generated based on the FE model described in the work by Gao and Dodds Jr. [30], so that total element number of 31,990 and node number of 139,816 do not change for specimen size. Using symmetry conditions, one-quarter of an SE(B) specimen containing a straight crack was analyzed, with appropriate constraints imposed on the symmetry planes, as illustrated in Figure 5. An initial blunted notch with a radius of $\rho=4.305 \mu \mathrm{m}$ was inserted at the crack-tip and "spiderweb" radius of $R_{s}=5.75 \mathrm{~mm}$ was selected to fully cover the high stress region for the $25 \mathrm{t}$ specimen. For all cases, 20 node isoparametric three-dimensional solid elements with reduced $(2 \times 2 \times 2)$ Gauss integration were employed. A load line displacement $V_{\mathrm{LL}}$ was applied for each EP-FEA. In the EPFEA, the applied load $P$ was measured as the total reaction force on the supported nodes. The $J$ simulated by the EPFEA, denoted as $J_{\mathrm{FEA}}$, was evaluated using a load-versuscrack-mouth opening displacement diagram $\left(P-V_{g}\right.$ diagram $)$, in accordance with ASTM E1921 [29]. CTOD was measured at node A in Figure 5 [31].

The mechanical properties of the test specimens are a Young's modulus $E$ of $206 \mathrm{GPa}$ and a Poisson's ratio $v$ of 0.3 . The FEA material behavior was assumed to be governed by the $J_{2}$ incremental theory of plasticity, the isotropic hardening rule, and the Prandtl-Reuss flow rule. Two total true stress-strain curves, shown in Figure 3(b), were averaged and used in the EP-FEA. WARP3D [32] was used as the FEA solver.

First, to validate the EP-FEA results, the EP-FEA $P-V_{g}$ diagram for the $25 \mathrm{t}$ specimen was compared with the 


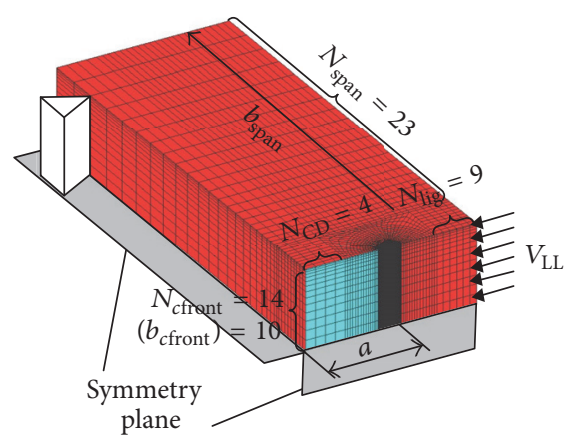

(a) Global mesh

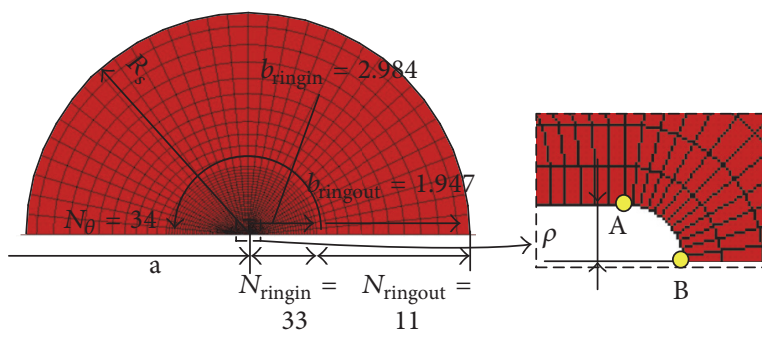

O Node A, B

$N_{\text {suffix }}$ : number of element for the suffix in the figure

$b_{\text {suffix }}$ : bias for the suffix in the figure

(b) Detail of crack-tip mesh

FIgURE 5: FE model for the SE(B) specimen.

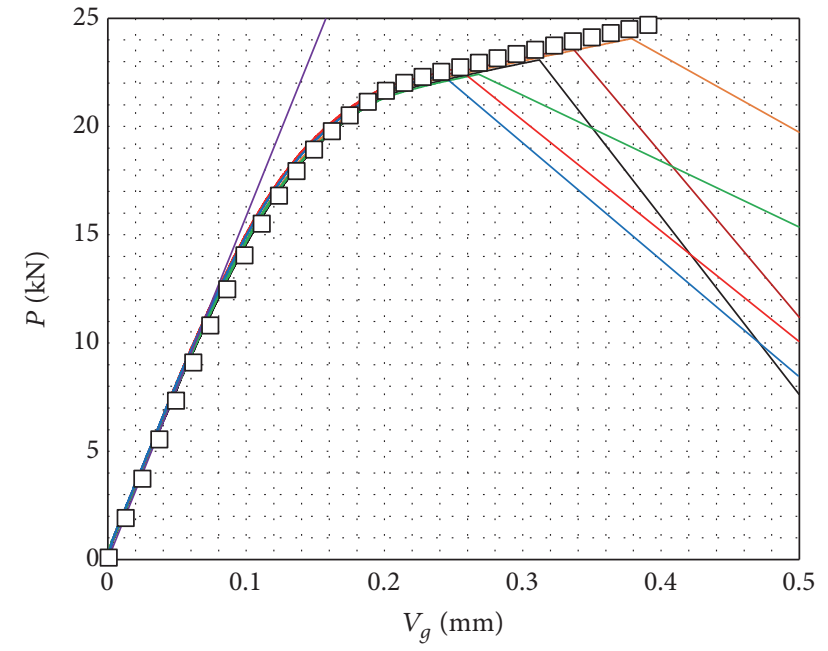

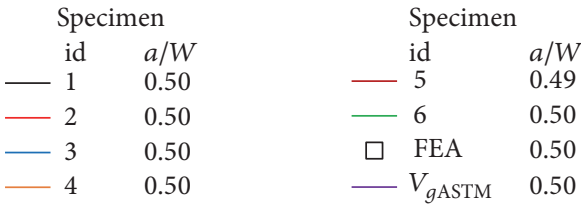

Figure 6: Comparison of the $P-V_{g}$ diagrams of the 25t SE(B) specimen: EP-FEA results shown with open rectangles show good agreement with the experimental results $\left(\mathrm{S} 55 \mathrm{C}, 20^{\circ} \mathrm{C}\right.$ ).

experimental results in Figure 6. The open rectangles represent the EP-FEA results.

As shown in Figure 6, the path of the EP-FEA $P-V_{g}$ diagram showed good agreement with the experimental results. Therefore, the EP-FEA result was considered to be valid and proceeded to obtain the critical stress $\sigma_{22 c}$.

The relationship between $\sigma_{22 d}$ (i.e., crack-opening stress measured at a distance from the crack-tip equal to $4 \delta_{t}$ on $x_{1}$-axis at the specimen midplane) and $J_{\mathrm{FEA}}$ for each load step was summarized in Figure 7. The stars in the figure indicate the fracture toughness values $\left(J_{c}\right.$ 's) obtained from the experiments.

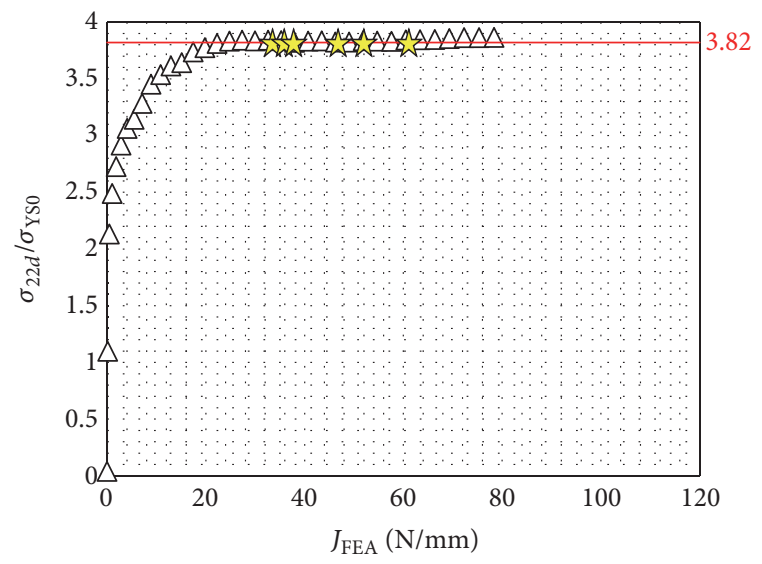

幽 $J_{c}$

Figure 7: The relationship between $\sigma_{22 d}$ and $J_{\mathrm{FEA}}$ of the $25 \mathrm{t} \mathrm{SE}(\mathrm{B})$ specimen $\left(\mathrm{S} 55 \mathrm{C}, 20^{\circ} \mathrm{C}\right.$ ): fracture always occurred after $\sigma_{22 d}$ reached $\sigma_{22 c}=3.82 \sigma_{\mathrm{YS} 0}$.

From this figure, it is revealed that fracture always occurred after $\sigma_{22 d}$ reached $3.82 \sigma_{\mathrm{Ys} 0}$; thus, this value was determined as the critical value $\sigma_{22 c}$ of the $\left(4 \delta_{t}, \sigma_{22 c}\right)$ criterion. If the criterion is applicable to miniaturized specimens, fracture is predicted when $\sigma_{22 d}$ for these miniaturized specimens reaches the identical critical value of $3.82 \sigma_{\text {YSO }}$.

\section{Applicability of the $\left(4 \delta_{t}, \sigma_{22 c}\right)$ Failure Criterion to Examine the Feasibility of Miniaturized Charpy Type SE(B) Specimens}

4.1. Selection of Miniaturized Specimen Size for Examination. Wallin et al. [33] noted that the minimum size of a Charpy type $\mathrm{SE}(\mathrm{B})$ specimen that satisfies the requirement of $M \geq 30$ for a RPV steel and tested at the temperature $T_{0}$ (master curve reference temperature) $\pm 50^{\circ} \mathrm{C}$ is a thickness of 5 and a width of $5 \mathrm{~mm}$ (hereinafter denoted as the 5t specimen). Considering that $T_{0}$ was approximately equal to $20^{\circ} \mathrm{C}$ for 


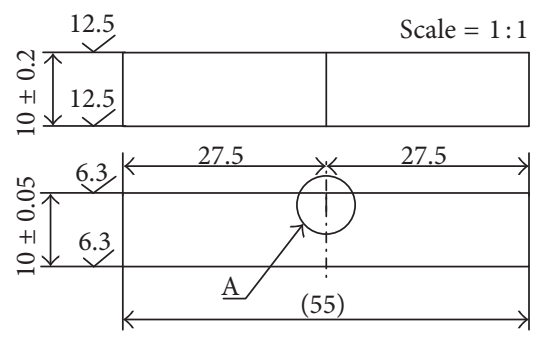

(a) $10 \mathrm{t}$

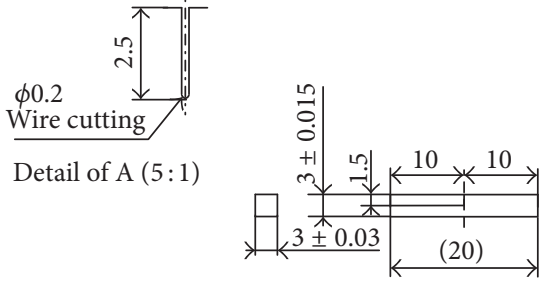

(b) $3 \mathrm{t}$

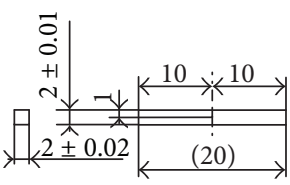

(c) $2 \mathrm{t}$

FIgURE 8: Dimensions of miniaturized SE(B) specimens.

S55C steel, the minimum size for the S55C steel to observe $K_{I_{c}}$ fracture was expected to be $5 \mathrm{t}$. However, some smaller specimens, such as 3.3t, have been examined in the past $[34,35]$. Because we are examining the feasibility of miniature specimens with $M<30$ to exhibit $K_{J_{c}}$ fracture, smaller specimens were also considered.

By using $J_{c}=33.5 \sim 61.1 \mathrm{~N} / \mathrm{mm}$ of $25 \mathrm{t}$ specimen and $\sigma_{\mathrm{Ys} 0}=$ $394 \mathrm{MPa}$ and assuming crack length $a=W / 2$ and $J_{c} \propto$ $B^{-1 / 2}$, the range of $M$ for $10 \mathrm{t}$ was estimated to be in the range of 20.4 37.2, that is, close to 30 . This is different from the abovementioned Wallin et al.s prediction. Thus, to be conservative, the 10t specimen was selected as the specimen for which $K_{I_{c}}$ fracture is expected. For the specimens below $M<30$, the $3 t$ specimen was selected as a candidate of $K_{I_{c}}$ fracture from the past experience of the $3.3 \mathrm{t}$ specimen (though there might be an opinion that the material and test temperature were different). The $2 t$ specimen was selected as a possible candidate for which $K_{J_{c}}$ fracture should not be observed.

The configurations of the $10 \mathrm{t}, 3 \mathrm{t}$, and $2 \mathrm{t} \mathrm{SE}(\mathrm{B})$ specimens are shown in Figure 8. The support span size was set as equal to $4 W$.

\subsection{Prediction of $K_{J_{c}}$ Cleavage Fracture and $J_{c}$ for Miniaturized} Specimens by Applying the $\left(4 \delta_{t}, \sigma_{22 c}\right)$ Criterion. EP-FEA was run for the $10 \mathrm{t}, 3 \mathrm{t}$, and $2 \mathrm{t}$ specimens shown in Figure 8 to predict whether $K_{J_{c}}$ cleavage fracture occurs. Details of EP-FEA are fundamentally identical to those for the $25 \mathrm{t}$ specimen, except the near crack-tip generated meshes; $\rho$ was in a range of 1.84 to $3.98 \mu \mathrm{m}$ and $R_{s}$ was in a range of 0.46 to $2.3 \mathrm{~mm}$. The relationships between $\sigma_{22 d}$ and $J_{\mathrm{FEA}}$ are shown in Figure 9. The value 3.82 in the figure indicates the critical value obtained from the $25 \mathrm{t}$ specimens.

From Figure 9(a), $K_{J_{c}}$ fracture was predicted for the $10 \mathrm{t}$ specimen because $\sigma_{22 d}$ reached the critical value $\sigma_{22 c}=$ $3.82 \sigma_{\mathrm{YS} 0}$ and the stress level was maintained for increasing load. The constancy of $\sigma_{22 d}$ for increasing load assures that even if a significant microcrack is not located at the original crack-tip, cleavage fracture might occur after small stable crack extension and a significant microcrack is encountered (SWL model). Thus, the minimum $J_{c}$ for the $10 t$ specimen was predicted as $58 \mathrm{~N} / \mathrm{mm}$ because $\sigma_{22 d}$ exceeded the critical value $\sigma_{22 c}$ when $J_{\mathrm{FEA}}$ reached $58 \mathrm{~N} / \mathrm{mm}$.

In contrast, $\sigma_{22 d}$ for the $3 \mathrm{t}$ and $2 \mathrm{t}$ specimens showed a maximum for increasing load; the stress level could not be maintained. Because $\sigma_{22 d}$ is measured at a variable location of $x_{1}=4 \delta_{t}$ and because $4 \delta_{t}$ increases with load, Figures 9(b) and 9(c) indicate that the region of high stress level does not continue to grow after the load $\sigma_{22 d}$ shows a maximum for $J_{\mathrm{FEA}}$. Thus, qualitatively, large stable crack extension was expected. This was the first experience for the $\left(4 \delta_{t}, \sigma_{22 c}\right)$ criterion and out of scope of what was considered within the criterion. However, because large stable crack extension was expected, $K_{J_{c}}$ fracture was not predicted for the $3 \mathrm{t}$ and $2 \mathrm{t}$ specimens.

4.3. Fracture Toughness Tests for the Miniaturized Specimen. Fracture toughness testing for the miniaturized specimen was conducted in accordance with ASTM E1921 [21]. The exception was the ligament size requirement of $M \geq 30$ and the quantity of the tests. The dimensions of the miniaturized $\mathrm{SE}(\mathrm{B})$ specimens are shown in Figure 8 . The $3 \mathrm{t}$ and $2 \mathrm{t}$ specimens were cut from the 10t specimen after the fatigue crack was inserted.

Fatigue precrack was inserted using loads corresponding to $K_{\max }=20 \mathrm{MPam}^{1 / 2}$ for both the 1st and final stage, which satisfied the requirement from the standard of $K_{\max } \leq 25$ and $20 \mathrm{MPam}^{1 / 2}$. For each discrete step, the reduction in $P_{\max }$ for any of these steps was $13-15 \%$, which satisfied the suggestion from the standard that the reduction in $P_{\max }$ for any of these steps be no greater than $20 \%$. The ratio of the maximum force $P_{\max }$ and the minimum force $P_{\min }$, or $R=P_{\min } / P_{\max }=0.1$, was used, and the loading frequency was $30 \mathrm{~Hz}$.

In the fracture toughness test, the loading rate was controlled to be within a specified range from 0.1 to 2.0 $\mathrm{MPam}^{1 / 2} / \mathrm{s}$, which resulted in an actual range between 0.12 and $1.4 \mathrm{MPam}^{1 / 2}$. In the following, the test results for the $10 \mathrm{t}$, $3 t$, and $2 \mathrm{t} \operatorname{SE}(\mathrm{B})$ specimens are described.

4.3.1. Test Results for the 10t SE(B) Specimens. The $P-V_{g}$ diagrams of the $10 \mathrm{t} \mathrm{SE}(\mathrm{B})$ specimens are compared with $V_{\text {gASTM }}^{g}$, which is the $V_{g}$ calculated from the elastic compliance given in ASTM E1820 [36].

As shown in Figure 10, the two experimental $P-V_{g}$ diagrams showed good reproducibility. Moreover, the linear slope of the experimental $P-V_{g}$ diagrams exhibited good agreement with the $P-V_{\text {gASTM }}$. Therefore, the experimental results of the 10t $\mathrm{SE}(\mathrm{B})$ specimens were considered to be valid and capable of being compared with the numerical predictions, despite the fact that only two tests were conducted. 


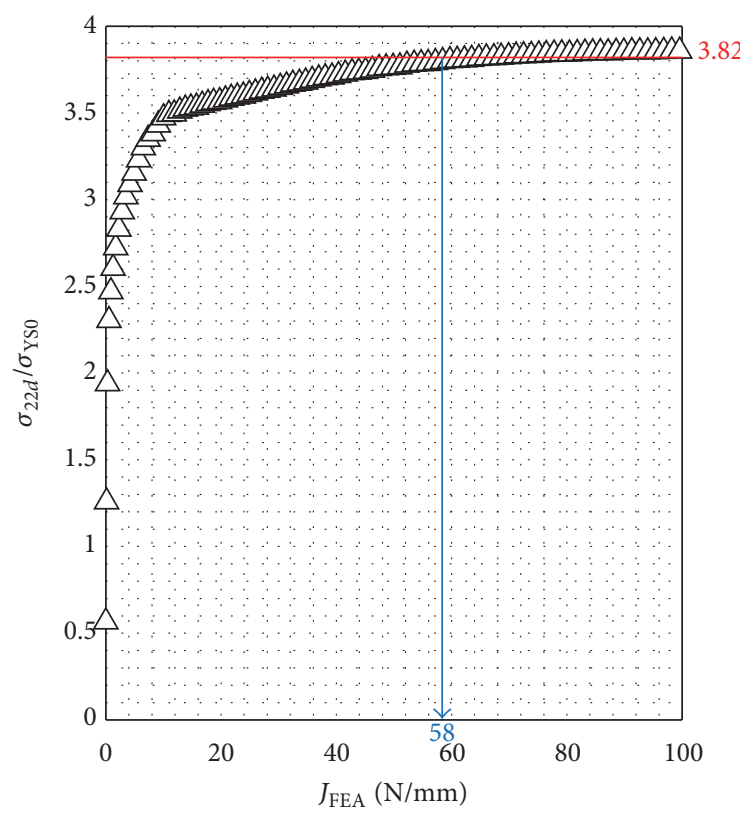

(a) $10 \mathrm{t}$

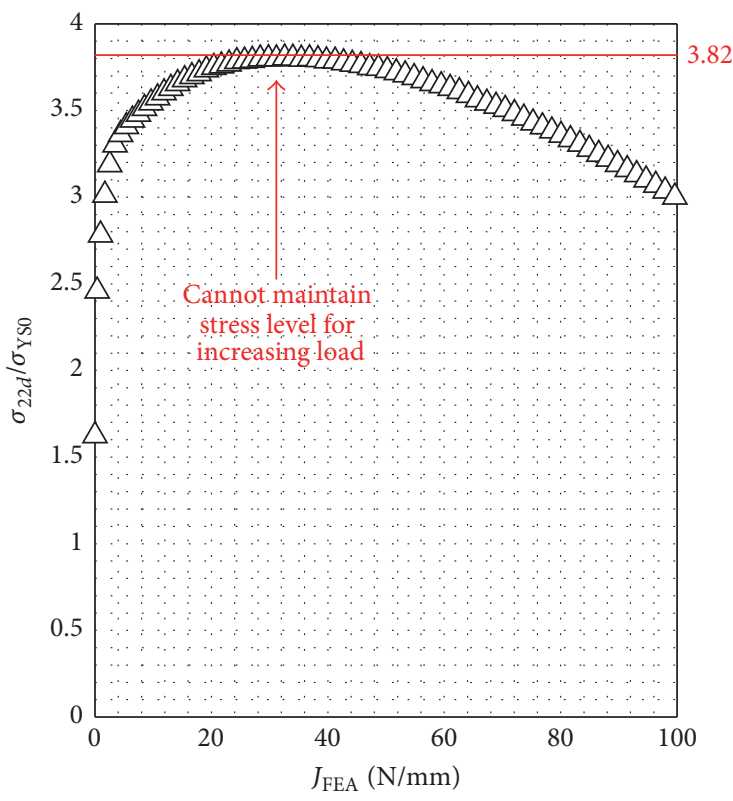

(b) $3 \mathrm{t}$

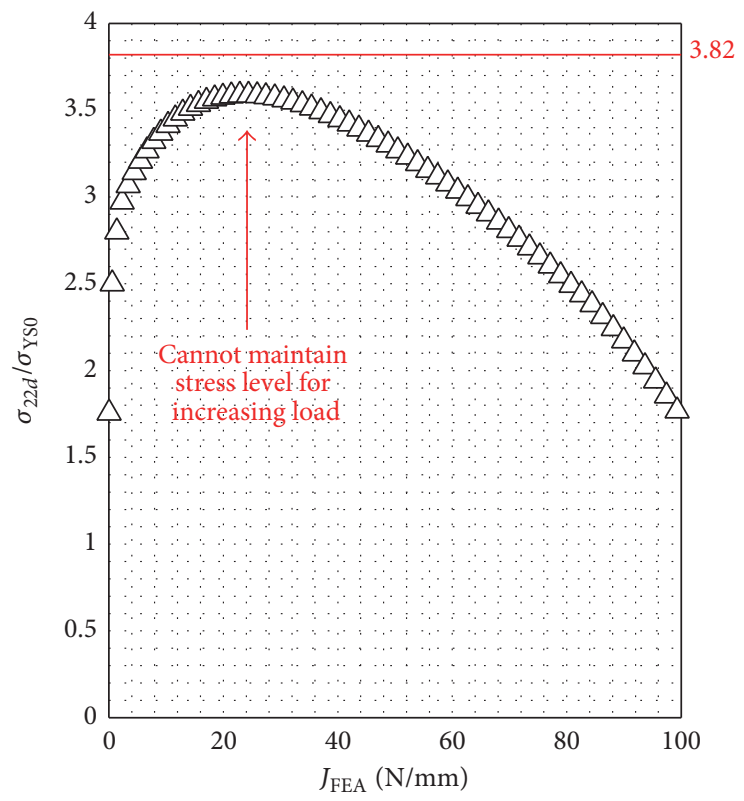

(c) $2 \mathrm{t}$

Figure 9: The relationships between $\sigma_{22 d}$ and $J_{\mathrm{FEA}}$ for the $10 \mathrm{t}, 3 \mathrm{t}$, and $2 \mathrm{t} \mathrm{SE}(\mathrm{B})$ specimens (S55C, $20^{\circ} \mathrm{C}$ ): $\sigma_{22 d}$ for $10 \mathrm{t}$ specimen reached the critical stress $\sigma_{22 c}$; the stress level was maintained for increasing $J_{\mathrm{FEA}}$, indicating occurrence of cleavage fracture within negligible stable crack extension ( $K_{J_{c}}$ fracture). In contrast, $\sigma_{22 d}$ for $3 \mathrm{t}$ and $2 \mathrm{t}$ specimens showed a maximum for increasing load, indicating low possibility of $K_{J_{c}}$ fracture.

The $P-V_{g}$ diagrams for both tests showed a sudden increase in $V_{g}$ after the maximum load was reached, indicating that the clip gauge dropped off. This suggested that an unstable fracture occurred.

The fracture surface of the $10 \mathrm{t}$ specimens clearly showed cleavage fracture after very small stable crack extension $\Delta a_{p}$, satisfying the ASTM E1921 requirement to be less than $\min ((W-a) / 20,1 \mathrm{~mm})=0.23 \mathrm{~mm}$. The values of the measured $\Delta a_{p}$ are listed in Table 2. Thus, the so-called
$K_{J_{c}}$ fracture was observed, as predicted with the $\left(4 \delta_{t}, \sigma_{22 c}\right)$ criterion.

Fracture toughness test results are summarized in Table 2. The average of $J_{c}=74.0 \mathrm{~N} / \mathrm{mm}$ was 1.7 times larger than that of the 25t SE(B) specimen. This magnification agreed with the empirical thickness relationship describing $J_{c}$, that is, $(10 / 25)^{-1 / 2}=1.6$. $M$ was close to but smaller than 30 , as predicted. Although only two data points were available, the standard deviation to the average ratio of $K_{J_{c}}$ was $7.75 \%$ for 

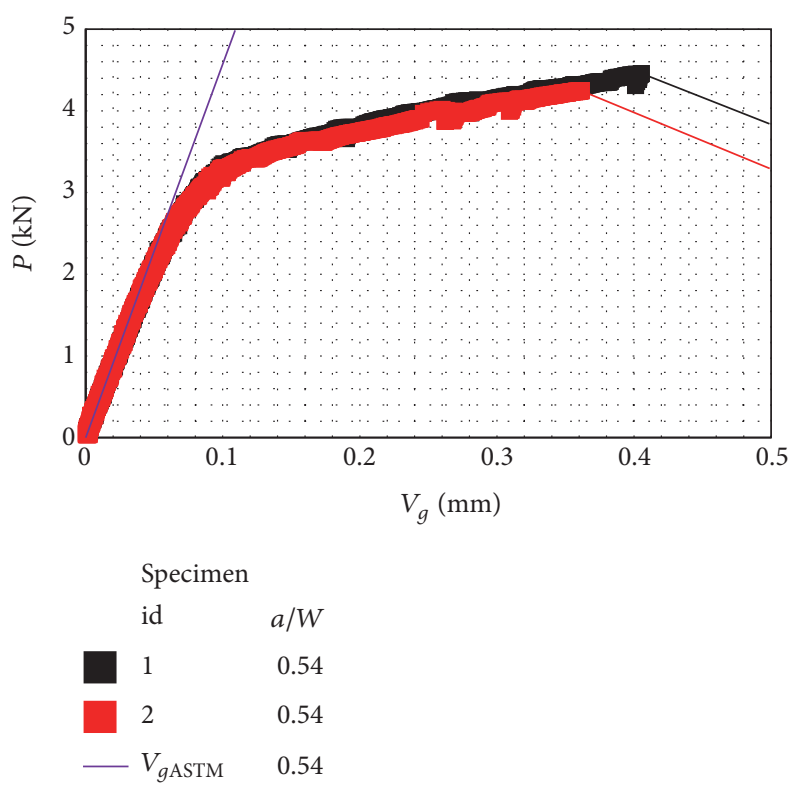

Figure 10: $P-V_{g}$ diagram of the 10t SE(B) specimens (S55C steel, $20^{\circ} \mathrm{C}$ ): $K_{J_{c}}$ fracture followed after relatively large plastic deformation.

TABLE 2: Fracture toughness test results of $10 \mathrm{t} \mathrm{SE}(\mathrm{B})$ specimens (S55C steel, $20^{\circ} \mathrm{C}$ ). Here, $\mu$ and $\Sigma$ denote the mean and standard deviation of each parameter, respectively. Though $M$ was smaller than 30 , cleavage fracture with negligible stable crack extension was observed.

\begin{tabular}{|c|c|c|c|c|c|}
\hline Specimen id & 1 & 2 & $\mu$ & $\Sigma$ & $2 \Sigma / \mu \%$ \\
\hline$a / W$ & 0.54 & 0.54 & 0.54 & 0 & \\
\hline$P_{c}(\mathrm{kN})$ & 4.46 & 4.25 & 4.36 & 0.105 & \\
\hline$K_{c}\left(\mathrm{MPam}^{1 / 2}\right)$ & 54.2 & 51.6 & 52.9 & 1.30 & \\
\hline$J_{c}(\mathrm{~N} / \mathrm{mm})$ & 79.8 & 68.1 & 74.0 & 5.85 & \\
\hline$K_{J_{c}}\left(\mathrm{MPam}^{1 / 2}\right)$ & 134 & 124 & 129 & 5.00 & 7.75 \\
\hline$\Delta a_{p}(\mathrm{~mm})$ & 0.13 & 0.02 & 0.075 & 0.055 & \\
\hline$M$ & 22.7 & 26.6 & 24.7 & 1.95 & \\
\hline
\end{tabular}

the current data, which was sufficiently small compared with the ASTM E1921 prediction of $2 \Sigma / \mu=56(1-20 / \mu) \%=47 \%$. Thus, from a fracture toughness standpoint, the experimental results for the $10 \mathrm{t} \mathrm{SE}(\mathrm{B})$ specimens were considered to be valid and capable of being compared with the numerical predictions, despite the fact that only two data points were obtained.

Considering the fact that the $a / W$ used in the EP-FEA was 0.50 , which was different from the experimental result of 0.54 , EP-FEA with $a / W=0.54$ was rerun, resulting in negligible small difference in the predicted minimum $J_{c}$ of $58 \mathrm{~N} / \mathrm{mm}$. Comparing the test results of $J_{c}=79.8$ and $68.1 \mathrm{~N} / \mathrm{mm}$ with the updated prediction, it was concluded that the $\left(4 \delta_{t}, \sigma_{22 c}\right)$ criterion could properly and consequently predict the minimum $J_{c}$ of the $10 \mathrm{t} \mathrm{SE}(\mathrm{B})$ specimen.

In summary, it was concluded that the $\left(4 \delta_{t}, \sigma_{22 c}\right)$ criterion could properly predict the occurrence of $K_{J_{c}}$ fracture and the minimum $J_{c}$ of the $10 \mathrm{t} \mathrm{SE}(\mathrm{B}) \mathrm{mm}$ specimen, despite the fact that the $M$ for the specimen did not satisfy ASTM E1921's requirement of $M \geq 30$.

4.3.2. Test Results for the $3 t$ and $2 t S E(B)$ Specimens. Fracture surfaces and $P-V_{g}$ diagrams of the $2 t$ and $3 t$ specimens are summarized in Figures 11 and 12, respectively. Note that $V_{g}=1 \mathrm{~mm}$ does not represent the value at final fracture, because the maximum measurement capacity of the clip gauge was this value. As expected, the $2 \mathrm{t}$ specimens in Figure 11 showed that large stable crack extension $\Delta a_{p}$ preceded before cleavage fracture, obviously not satisfying the ASTM E1921 requirement of $\Delta a_{p}<(W-a) / 20$. Thus, the $\left(4 \delta_{t}, \sigma_{22 c}\right)$ criterion properly predicted the nonoccurrence of $K_{J_{c}}$ fracture for the $2 \mathrm{t} \mathrm{SE(B)} \mathrm{specimen.}$

$P-V_{g}$ diagrams for the $3 t$ specimens (Figure 12(b)) were different from those of the $2 \mathrm{t}$ specimens; that is, specimen id 1 showed "pop-in" phenomena. From the fracture surface of specimen id 1 in Figure 12(a), this pop-in was correlated with one of the two significant cleavage fracture areas on the fracture surface. Because ASTM E1921 states that "all pop-in crack initiation $K$ values for cracks that advance by a cleavage-driven mechanism are to be regarded as eligible $K_{J_{c}}$ data," specimen id 1 showed $K_{J_{c}}$ fracture. This might have some relationship with the fact that $\sigma_{22 d}$ exceeded $\sigma_{22 c}$ for the $3 t \operatorname{SE}(B)$ specimen, but further study in the future is necessary. The fracture surface of specimen id 2 showed an obviously large stable crack extension. In summary, one of the two $3 t$ specimens did not show $K_{J_{c}}$ fracture. Thus, it was 


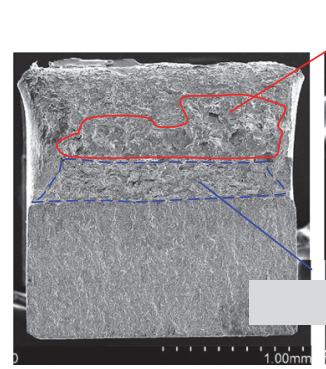

1
Cleavage fracture

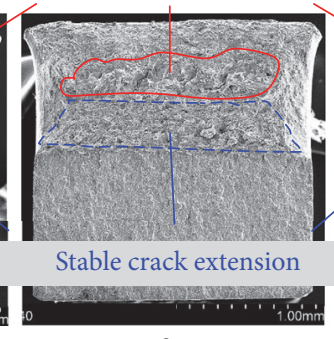

2
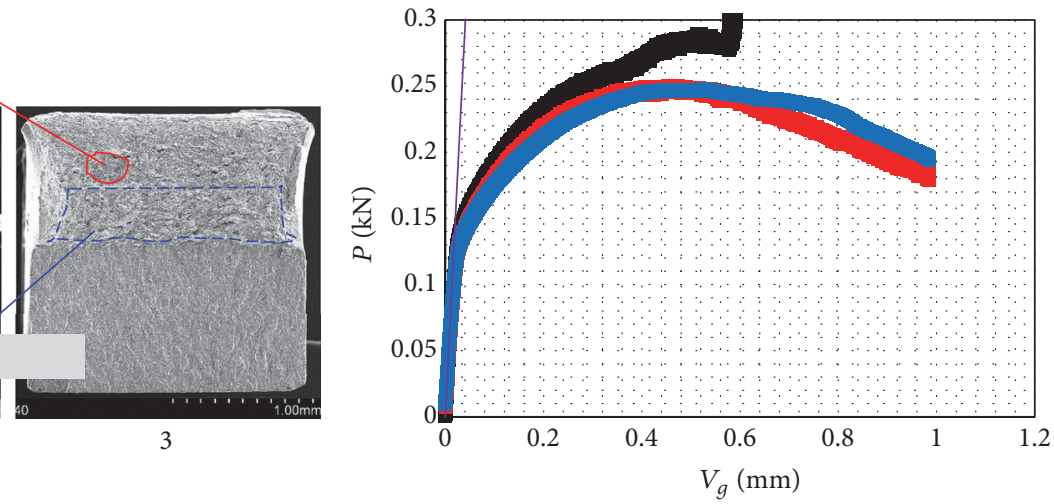

\begin{tabular}{cccc}
\multicolumn{2}{l}{ Specimen } & \multicolumn{2}{c}{ Specimen } \\
id & $a / W$ & id & $a / W$ \\
1 & 0.50 & 3 & 0.53 \\
2 & 0.52 & $-V_{\text {gASTM }}$ & 0.50 \\
& -0.53
\end{tabular}

FIGURE 11: Fracture surfaces and load $P$ versus crack-mouth opening displacement $V_{g}$ diagrams of the 2t SE(B) specimens (S55C, $\left.20^{\circ} \mathrm{C}\right)$. Large stable crack extension before cleavage fracture was observed, as predicted from the $\left(4 \delta_{t}, \sigma_{22 c}\right)$ failure criterion. Note that $V_{g}=1 \mathrm{~mm}$ does not correspond to the final fracture.
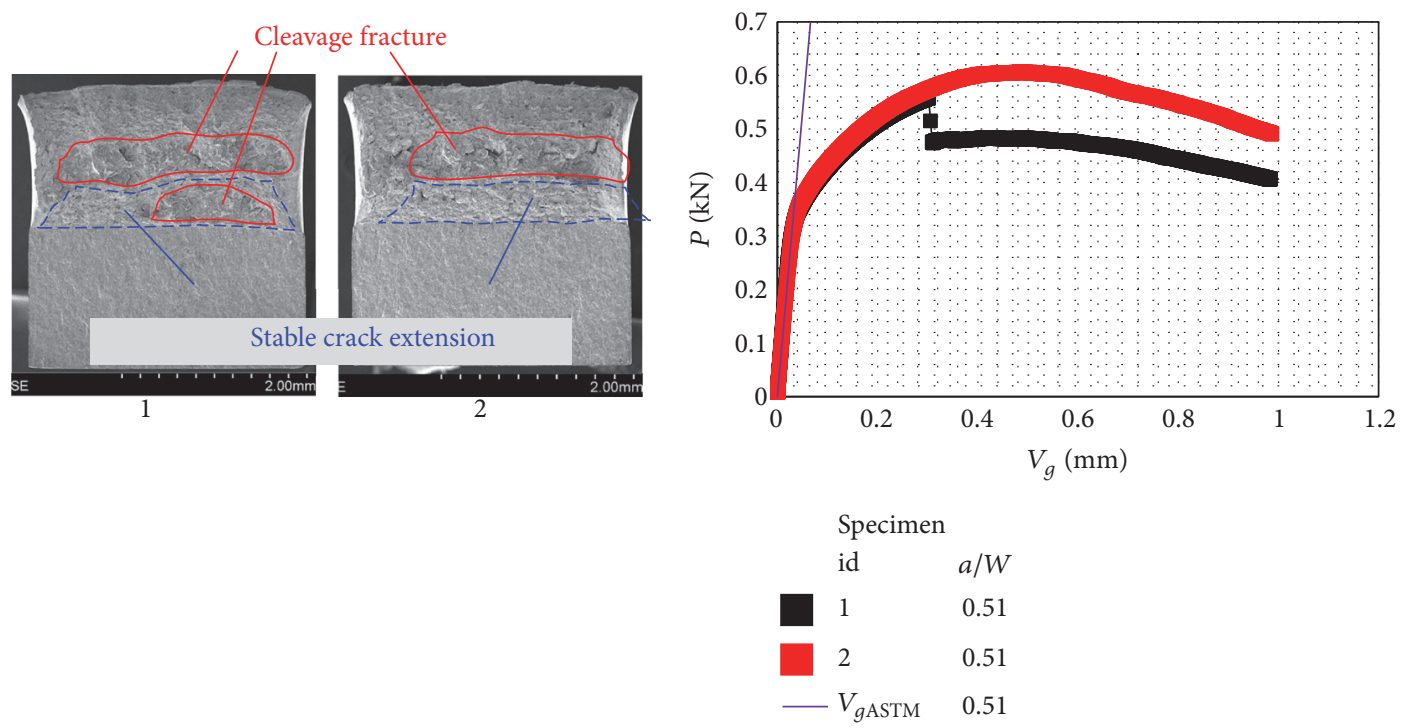

(a)

(b)

Figure 12: Fracture surfaces and load $P$ versus crack-mouth opening displacement $V_{g}$ diagrams of the $3 \mathrm{t}$ SE(B) specimens (S55C, 20 $0^{\circ} \mathrm{C}$ ). Pop-in correlated with cleavage mechanism was observed for specimen id 1. However, large stable crack extension before cleavage fracture was observed for specimen id 2, as predicted from the $\left(4 \delta_{t}, \sigma_{22 c}\right)$ failure criterion. Note that $V_{g}=1 \mathrm{~mm}$ does not correspond to the final fracture.

concluded that the $\left(4 \delta_{t}, \sigma_{22 c}\right)$ criterion properly predicted the nonoccurrence of $K_{J_{c}}$ fracture for the $3 \mathrm{t} \mathrm{SE}(\mathrm{B})$ specimen.

In summary, it was concluded that the $\left(4 \delta_{t}, \sigma_{22 c}\right)$ criterion could appropriately predict invalid $K_{J_{c}}$ fracture for the $2 \mathrm{t}$ and 3t $\mathrm{SE}(\mathrm{B})$ specimens.

\section{Discussion}

This paper examined whether the $\left(4 \delta_{t}, \sigma_{22 c}\right)$ failure criterion was applicable to the miniaturized $\mathrm{SE}(\mathrm{B})$ specimens. Past experience of application of the criterion to small $\mathrm{SE}(\mathrm{B})$ was for $(W, B)=(6.4,15.9)$ and $(12.7,8) \mathrm{mm}$ for A533B steel [18]. The guideline of the minimum miniaturized Chary type SE(B) specimen satisfying the ASTM E1921 requirements (e.g., $M \geq 30$ and stable crack extension $\Delta a_{p}<(W-a) / 20$; described as $K_{J_{c}}$ fracture in this paper) was known to be $5 \mathrm{t}$ in size [33]. Considering the restriction $M \geq 30$ for the material S55C and these backgrounds, 2t-, 3t-, 10t-, and 25tsized Charpy type SE(B) were examined. Focus was placed on (1) whether the criterion could predict the occurrence of $K_{J_{c}}$ 
fracture and (2) whether $\sigma_{22 c}$ is identical to that observed in full-sized specimens in the case where $K_{J_{c}}$ fracture occurred.

Regarding point (1), the results showed that the $\left(4 \delta_{t}, \sigma_{22 c}\right)$ criterion could appropriately predict a $K_{J_{c}}$ fracture naturally for specimens for the $25 \mathrm{t}$ and $10 \mathrm{t}$ specimens. The $\left(4 \delta_{t}, \sigma_{22 c}\right)$ criterion could also predict that $K_{J_{c}}$ fracture does not occur for the $3 \mathrm{t}$ and $2 \mathrm{t}$ specimens if the necessary condition, that is, "the stress level of $\sigma_{22 d}$ is maintained as $\sigma_{22 c}$ for increasing load," is explicitly considered. This necessary condition was not stated in the original proposal of the criterion [3] but seems to be automatically satisfied for ordinary-sized specimens whose $M \gg 30$. Because $\sigma_{22 d}$ is measured at a variable location of $x_{1}=4 \delta_{t}$ and because $4 \delta_{t}$ increases with load to reflect the stable crack extension, cases such as Figures 9(b) and 9(c) indicate that the region of high stress level ahead of the crack cannot be maintained after the load $\sigma_{22 d}$ shows a maximum for $J_{\mathrm{FEA}}$. Thus, qualitatively, large stable crack extension was expected.

Regarding point (2), $\sigma_{22 c}$ obtained from the $10 \mathrm{t}$ specimen exhibited only a small difference with that of $25 \mathrm{t}$. The minimum $J_{\mathrm{FEA}}$ that could satisfy $\sigma_{22 d}=\sigma_{22 c}$ for the $10 \mathrm{t}$ specimen conservatively predicted experimental $J_{c}$. The process can definitely be applied to the reverse case; $\sigma_{22 c}$ obtained from the $10 \mathrm{t} \mathrm{mm}$ specimen can be used to predict the $J_{c}$ obtained from the $25 \mathrm{t}$ specimens.

In summary, the results from this work appear to demonstrate the applicability of the modified Ritchie-Knott-Rice (i.e., $\left.\left(4 \delta_{t}, \sigma_{22 c}\right)\right)$ failure criterion for examining the feasibility of miniaturized Charpy type $\mathrm{SE}(\mathrm{B})$ specimens. It is expected that if a $K_{J_{c}}$ fracture is predicted by the $\left(4 \delta_{t}, \sigma_{22 c}\right)$ criterion and the implicit necessary condition (i.e., "the stress level of $\sigma_{22 d}$ is maintained as $\sigma_{22 c}$ for increasing load") is satisfied for a miniaturized SE(B) specimen for a specific material and temperature, it is possible to transfer $J_{c}$ obtained using this miniaturized specimen to the $J_{c}$ expected for a $25 \mathrm{t} \mathrm{SE}(\mathrm{B})$ specimen.

There might be an opinion that in the experiments cleavage fracture occurs after microductile (or stable) crack extension, whereas in the FE-modeling a stationary crack without crack extension is treated. Strictly speaking, the current FE-modeling reflects some crack extension due to crack-tip blunting, which has been understood to correspond to the stretch-zone. Though the stable crack extension is very large compared with this stretch-zone, the conclusions of the current study are considered as valid, because the effect of the crack-length on the critical stress $\sigma_{22 c}$ is small. The $\left(4 \delta_{t}, \sigma_{22 c}\right)$ criterion was originally proposed to transfer $J_{c}$ 's obtained with specimens of different crack length [3] and $\sigma_{22 c}$ was the critical value that is independent of the crack length.

There might be another opinion that the condition "stress level of $\sigma_{22 d}$ is maintained for increasing load" is questionable. However, it has long been known that crack-tip stress distribution reaches a steady state above some load level if distance from the crack-tip is normalized as $\left(r \sigma_{\mathrm{Ys} 0} / J\right)$ [31]. Usually, $\delta_{t}$ has a linear relationship with $J$ in this load range; thus, $\sigma_{22 d}$ is expected to be constant and independent of $J$. Considering the fact that $K_{I_{c}}$ fracture was always observed to occur after $\sigma_{22 d}$ reached $\sigma_{22 c}$ for A533B steel [20] and for
S55C steel in this work and in [14], the minimum $J$ that can satisfy $\sigma_{22 d}=\sigma_{22 c}$ seems to correspond to the minimum $J_{c}$ observed with the specimen configuration and the material at a specific temperature. This finding is consistent with the opinion of Chen et al. that "the minimum fracture toughness is a definite parameter determined by the specimen geometry and yielding properties" [26] and will be examined in more detail in the future.

\section{Conclusions}

This paper examined whether the $\left(4 \delta_{t}, \sigma_{22 c}\right)$ failure criterion, which is one of the modified RKR criteria, was applicable to the miniaturized Charpy type $\mathrm{SE}(\mathrm{B})$ specimens, that is, (1) whether the criterion could predict the occurrence of cleavage fracture accompanied by negligibly small stable crack extension (denoted as $K_{J_{c}}$ fracture in this paper) and (2) whether $\sigma_{22 c}$ is identical to that observed in full-sized specimens in the case where $K_{J_{c}}$ fracture occurred. $25 \mathrm{t}$, $10 t, 3 t$, and $2 t$ Charpy type $\mathrm{SE}(\mathrm{B})$ specimens manufactured with $\mathrm{S} 55 \mathrm{C}$ steel were tested at $20^{\circ} \mathrm{C}$. The results showed that the $\left(4 \delta_{t}, \sigma_{22 c}\right)$ criterion could appropriately distinguish the occurrence of $K_{J_{c}}$ fracture, by explicitly considering the necessary condition (i.e., "the stress level of $\sigma_{22 d}$ is maintained as $\sigma_{22 c}$ for increasing load") with the original criterion (i.e., " $K_{J_{c}}$ fracture occurs when $\sigma_{22 d}$ exceeds a critical value $\sigma_{22 c}$ "). The $\sigma_{22 c}$ obtained for the $25 \mathrm{t}$ and $10 \mathrm{t}$ specimens exhibited only a small difference, indicating that $J_{c}$ obtained from the $10 \mathrm{t} \mathrm{mm}$ specimens can be used to predict the $J_{c}$ that will be obtained with the $25 \mathrm{t}$ specimens.

\section{Nomenclature}

$\begin{array}{ll}B: & \text { Specimen thickness } \\ E: & \text { Young's modulus } \\ J: & J \text {-integral } \\ J_{c}: & \text { Fracture toughness } \\ J_{\mathrm{FEA}}: & \text { J obtained from FEA } \\ K_{c}: & \text { SIF corresponding to the fracture load } \\ & P_{c} \\ K_{J_{c}}: & \text { Cleavage fracture toughness }= \\ & {\left[E J_{c} /\left(1-v^{2}\right)\right]^{1 / 2}} \\ M: & \text { Parameter that gives information } \\ & \text { regarding the initial ligament size to } \\ & \text { fracture process zone size: } \\ P: & \left(=\left(b_{0} \sigma_{\mathrm{Ys} 0}\right) / J_{c}\right) \\ P_{c}: & \text { Load } \\ V_{g}: & \text { Fracture load } \\ W: & \text { Crack-mouth opening displacement } \\ a: & (\text { CMOD }) \\ \Delta a_{p}: & \text { Specimen width } \\ b_{0}: & \text { Crack length } \\ \delta_{t}: & \text { Stable crack extension } \\ v: & \text { Initial ligament size: }(=(W-a)) \\ & \text { Crack-tip opening displacement } \\ & \text { (CTOD) } \\ & \text { Poisson's ratio }\end{array}$




$\begin{array}{ll}\sigma_{\mathrm{B}}, \sigma_{\mathrm{B} 0}: & \text { True and nominal tensile strength } \\ \sigma_{\mathrm{YS}}, \sigma_{\mathrm{YS} 0}: & \text { True and nominal yield stress } \\ \sigma_{22}: & \text { Crack-opening stress } \\ \sigma_{22 c}: & \text { Critical crack-opening stress } \\ & \sigma_{22} \text { measured at a distance from the } \\ \sigma_{22 d}: & \text { crack-tip equal to four times } \delta_{t} \text { at the } \\ \text { 25t, 10t, 3t, and 2t } & \text { SEecimen midplane } \\ \text { specimens: } & \text { values of } 25,10,3 \text {, and } 2 \text { mm } \\ & \text { Specimens which resulted with cleavage } \\ K_{J_{c}} \text { fracture: } & \text { fracture which satisfied ASTM E1921 } \\ & \text { requirement of } \\ \text { ASTM: } & \text { A } a_{p}<\text { min }((W-a) / 20 \text { or } 1 \text { mm }) \\ \text { A533B: } & \text { American Society for Testing and } \\ \text { CTOD: } & \text { Materials } \\ \text { DBTT: } & \text { ASTM A533 Grade B class 1 steel } \\ \text { EP-FEA: } & \text { Crack-tip opening displacement } \\ \text { IAEA: } & \text { Ductile-to-brittle transition } \\ \text { JIS: } & \text { temperature } \\ \text { RPV: } & \text { Elastic-plastic finite element analysis } \\ \text { S55C: } & \text { International Atomic Energy Agency } \\ \text { SE(B): } & \text { Japanese Industrial Standards } \\ \text { SWL: } & \text { Reactor pressure vessel } \\ \text { TST: } & \text { JIS 0.55\% carbon steel } \\ & \text { Single-edge notched bend bar } \\ & \text { Statistical weakest link } \\ & \text { Test specimen thickness. }\end{array}$

\section{Competing Interests}

The authors declare that they have no competing interests.

\section{Acknowledgments}

Part of this work was supported by Chubu electric power's research based on the selected proposals. This support and Dr. Hideki Yuya's advice were greatly appreciated. Discussion with Dr. Hiroaki Kurishita, former Professor at Tohoku University was also helpful. Testing of miniaturized SE(B) specimens was conducted as a joint research work between the authors and Kobe Material Testing Laboratory Co., Ltd. Mr. Kazuto Nakadate, Mr. Katsuya Taguchi, Ms. Yuriko Inoue, Mr. Kazukiyo Takahashi, Mr. Katsuki Yoshioka, Mr. Yoshihiro Saeki, and Mr. Satoshi Yuki contributed to the testing and are appreciated.

\section{References}

[1] IAEA, Master Curve Approach to Monitor Fracture toughness of Reactor Pressure Vessels in Nuclear Power Plants, IAEA, 2009.

[2] K. Wallin, "The size effect in $K_{\mathrm{IC}}$ results," Engineering Fracture Mechanics, vol. 22, no. 1, pp. 149-163, 1985.

[3] R. H. Dodds, T. L. Anderson, and M. T. Kirk, "A framework to correlate $a / W$ ratio effects on elastic-plastic fracture toughness (Jc)," International Journal of Fracture, vol. 48, no. 1, pp. 1-22, 1991.

[4] M. T. Kirk, R. H. Dodds, and T. L. Anderson, "An approximate technique for predicting size effects on cleavage fracture toughness $\left(J_{c}\right)$ using the elastic T stress," in STP 1207, Fracture Mechanics, J. D. Landes, D. E. McCabe, and J. A. M. Boulet, Eds., vol. 24, American Society for Testing and Materials, pp. 62-86, Philadelphia, Pa, USA, 1994.

[5] T. L. Anderson, D. Stienstra, and R. H. Dodds, "A theoretical framework for addressing fracture in the ductile-brittle transition region," in Fracture Mechanics: 24th Volume, J. D. Landes, D. E. McCabe, and J. A. M. Boulet, Eds., STP1207, pp. 186-214, American Society for Testing and Materials, Philadelphia, Pa, USA, 1994.

[6] M. Nevalainen and R. H. Dodds Jr., "Numerical investigation of 3-D constraint effects on brittle fracture in $\mathrm{SE}(\mathrm{B})$ and $\mathrm{C}(\mathrm{T})$ specimens," International Journal of Fracture, vol. 74, no. 2, pp. 131-161, 1995.

[7] T. J. Theiss and J. W. Bryson, "Influence of crack depth on the fracture toughness of reactor pressure vessel steel," in STP 1171, Constraint Effects in Fracture, E. M. Hackett, Ed., pp. 104-119, ASTM International, 1993.

[8] J. D. G. Sumpter, "An experimental investigation of the T stress approach," in STP 1171, Constraint Effects in Fracture, E. M. Hackett, K.-H. Schwalbe, and R. H. Dodds, Eds., pp. 495-502, American Society for Testing and Materials, 1993.

[9] M. T. Kirk, K. C. Koppenhoefer, and C. F. Shih, "Effect of constraint on specimen dimensions needed to obtain structurally relevant toughness measures," in STP 1171, Constraint Effects in Fracture, E. M. Hackett, Ed., pp. 79-103, American Society for Testing and Materials, West Conshohocken, Pa, USA, 1993.

[10] H. J. Rathbun, G. R. Odette, M. Y. He, and T. Yamamoto, "Influence of statistical and constraint loss size effects on cleavage fracture toughness in the transition-a model based analysis," Engineering Fracture Mechanics, vol. 73, no. 18, pp. 2723-2747, 2006.

[11] T. Meshii and T. Tanaka, "Experimental $T_{33}$-stress formulation of test specimen thickness effect on fracture toughness in the transition temperature region," Engineering Fracture Mechanics, vol. 77, no. 5, pp. 867-877, 2010.

[12] T. Meshii, T. Tanaka, and K. Lu, "T-stress solutions for a semi-elliptical axial surface crack in a cylinder subjected to mode-I non-uniform stress distributions," Engineering Fracture Mechanics, vol. 77, no. 13, pp. 2467-2478, 2010.

[13] T. Meshii, K. Lu, and R. Takamura, "A failure criterion to explain the test specimen thickness effect on fracture toughness in the transition temperature region," Engineering Fracture Mechanics, vol. 104, pp. 184-197, 2013.

[14] K. Lu and T. Meshii, "Application of $T_{33}$-stress to predict the lower bound fracture toughness for increasing the test specimen thickness in the transition temperature region," Advances in Materials Science and Engineering, vol. 2014, Article ID 269137, 8 pages, 2014.

[15] K. Lu and T. Meshii, “Three-dimensional T-stresses for threepoint-bend specimens with large thickness variation," Engineering Fracture Mechanics, vol. 116, pp. 197-203, 2014.

[16] K. Lu and T. Meshii, "A systematic investigation of T-stresses for a variety of center-cracked tension specimens," Theoretical and Applied Fracture Mechanics, vol. 77, pp. 74-81, 2015.

[17] T. Meshii, K. Lu, and Y. Fujiwara, "Extended investigation of the test specimen thickness (TST) effect on the fracture toughness $\left(J_{c}\right)$ of a material in the ductile-to-brittle transition temperature region as a difference in the crack tip constraint-what is the loss of constraint in the TST effects on $J_{c}$ ?" Engineering Fracture Mechanics, vol. 135, pp. 286-294, 2015. 
[18] T. Meshii and T. Yamaguchi, "Applicability of the modified Ritchie-Knott-Rice failure criterion to transfer fracture toughness $J_{c}$ of reactor pressure vessel steel using specimens of different thicknesses-possibility of deterministic approach to transfer the minimum $J_{c}$ for specified specimen thicknesses," Theoretical and Applied Fracture Mechanics, vol. 85, pp. 328344, 2016.

[19] V. F. González-Albuixech, E. Giner, J. Fernández-Sáez, and A. Fernández-Canteli, "Influence of the $T_{33}$-stress on the 3-D stress state around corner cracks in an elastic plate," Engineering Fracture Mechanics, vol. 78, no. 2, pp. 412-427, 2011.

[20] R. Seifi, A. H. Mahmoudi, and M. Babalhavaeji, "J-integral and CMOD for external inclined cracks on autofrettaged cylinders," International Journal of Fracture, vol. 169, no. 2, pp. 199-212, 2011.

[21] Y. G. Matvienko, V. N. Shlyannikov, and N. V. Boychenko, "Inplane and out-of-plane constraint parameters along a threedimensional crack-front stress field under creep loading," Fatigue \& Fracture of Engineering Materials \& Structures, vol. 36, no. 1, pp. 14-24, 2013.

[22] G. Qian, V. F. Gonzalez-Albuixech, and M. Niffenegger, "Inplane and out-of-plane constraint effects under pressurized thermal shocks," International Journal of Solids and Structures, vol. 51, no. 6, pp. 1311-1321, 2014.

[23] V. N. Shlyannikov, N. V. Boychenko, A. V. Tumanov, and A. Fernández-Canteli, "The elastic and plastic constraint parameters for three-dimensional problems," Engineering Fracture Mechanics, vol. 127, pp. 83-96, 2014.

[24] M. Gupta, R. C. Alderliesten, and R. Benedictus, "A review of Tstress and its effects in fracture mechanics," Engineering Fracture Mechanics, vol. 134, pp. 218-241, 2015.

[25] M. Y. Mu, G. Z. Wang, F. Z. Xuan, and S. T. Tu, "Unified correlation of in-plane and out-of-plane constraints with cleavage fracture toughness," Theoretical and Applied Fracture Mechanics, vol. 80, pp. 121-132, 2015.

[26] J. H. Chen, G. Z. Wang, C. Yan, H. Ma, and L. Zhu, "Advances in the mechanism of cleavage fracture of low alloy steel at low temperature. Part II: fracture model," International Journal of Fracture, vol. 83, no. 2, pp. 121-138, 1997.

[27] JIS, Z2242 Method of Impact Test for Metallic Materials, Japanese Industrial Standards Committee, Tokyo, Japan, 1998.

[28] JIS, Z2241 Method of Tensile Test for Metallic Materials, Japanese Industrial Standards Committee, Tokyo, Japan, 1998.

[29] ASTM, "E1921-10 Standard test method for determination of reference temperature, $T_{0}$, for ferritic steels in the transition range," in Annual Book of ASTM Standards, American Society for Testing and Materials, Philadelphia, Pa, USA, 2010.

[30] X. Gao and R. H. Dodds Jr., "Constraint effects on the ductileto-brittle transition temperature of ferritic steels: a Weibull stress model," International Journal of Fracture, vol. 102, no. 1, pp. 43-69, 2000.

[31] R. M. McMeeking, "Finite deformation analysis of cracktip opening in elastic-plastic materials and implications for fracture," Journal of the Mechanics and Physics of Solids, vol. 25, no. 5, pp. 357-381, 1977.

[32] A. Gullerud, K. C. Koppenhoefer, Y. Roy, S. RoyChowdhury, M. Walters, and R. H. Dodds, WARP3D Release 17.5.3 Manual, University of Illinois at Urbana-Champaign, Champaign, Ill, USA, 2014.

[33] K. Wallin, T. Planman, M. Valo, and R. Rintamaa, "Applicability of miniature size bend specimens to determine the master curve reference temperature $T_{0}$, Engineering Fracture Mechanics, vol. 68, no. 11, pp. 1265-1296, 2001.

[34] E. Wakai, S. Nogami, R. Kasada et al., "Small specimen test technology and methodology of IFMIF/EVEDA and the further subjects," Journal of Nuclear Materials, vol. 417, no. 1-3, pp. 13251330, 2011.

[35] H. Kurishita, T. Yamamoto, T. Nagasaka, A. Nishimura, T. Muroga, and S. Jitsukawa, "Fracture toughness of JLF-1 by miniaturized 3-point bend specimens with 3.3-7.0 mm thickness," Materials Transactions, vol. 45, no. 3, pp. 936-941, 2004.

[36] ASTM E1820-06a, "Standard test method for measurement of fracture toughness," in Annual Book of ASTM Standards, American Society for Testing and Materials, Philadelphia, Pa, USA, 2006. 

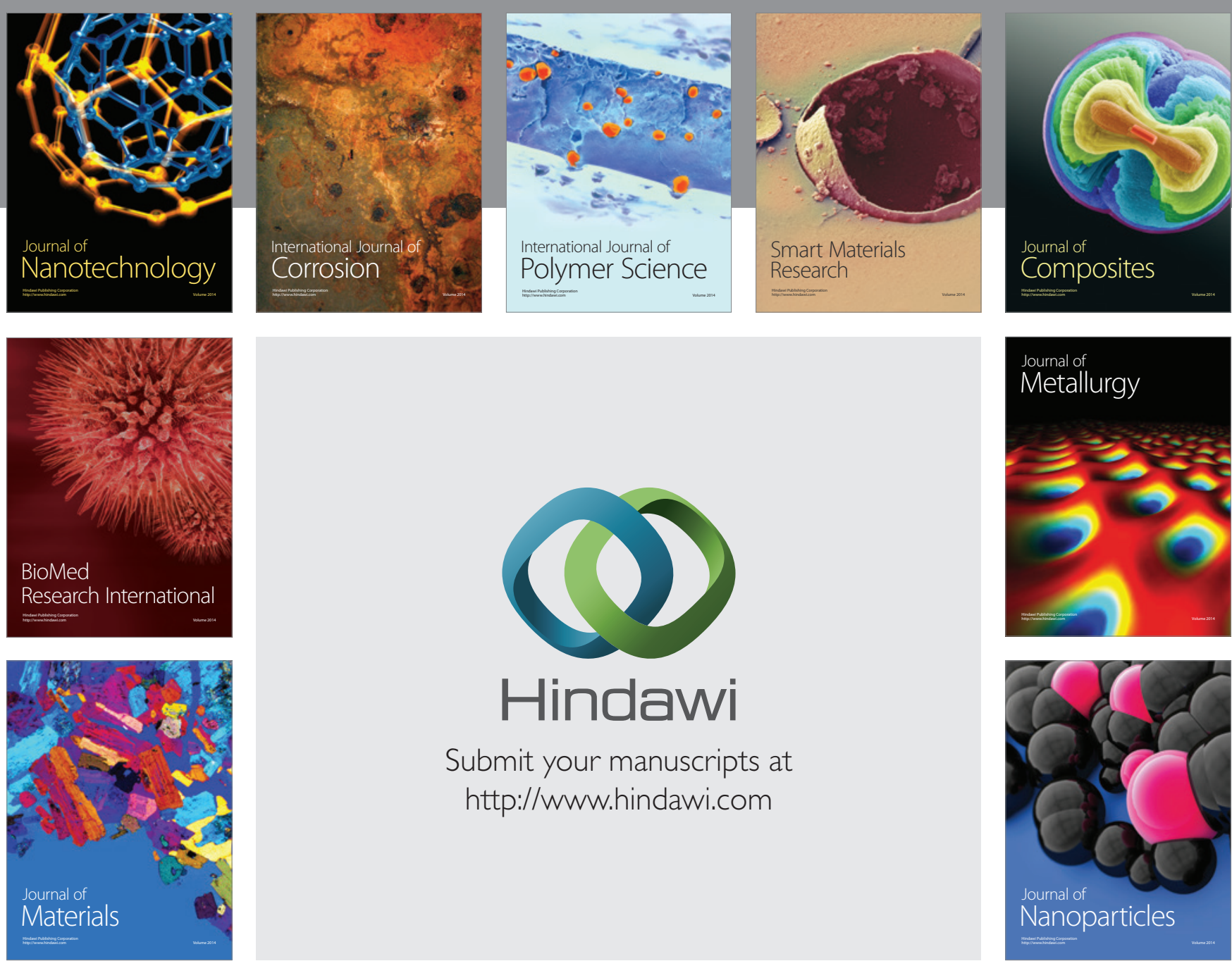

\section{Hindawi}

Submit your manuscripts at

http://www.hindawi.com

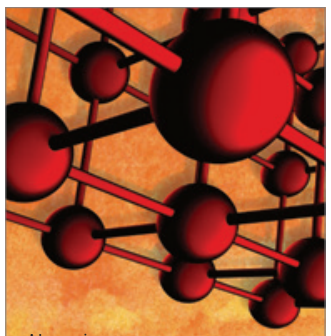

Materials Science and Engineering
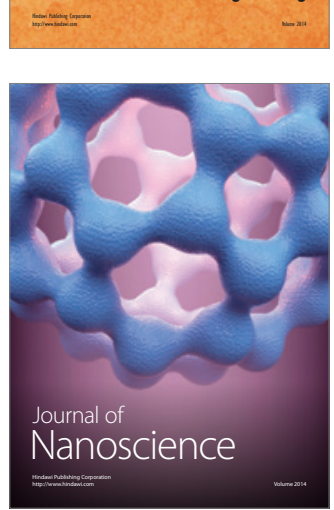
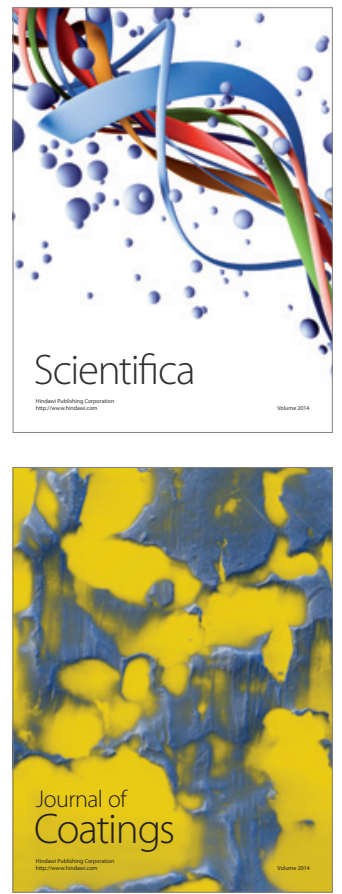
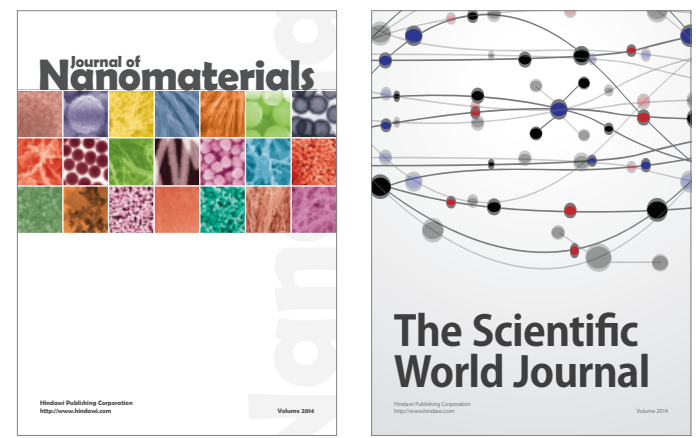

The Scientific World Journal
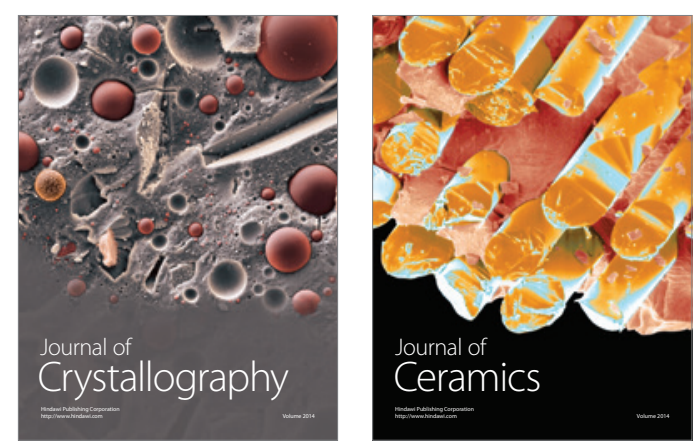
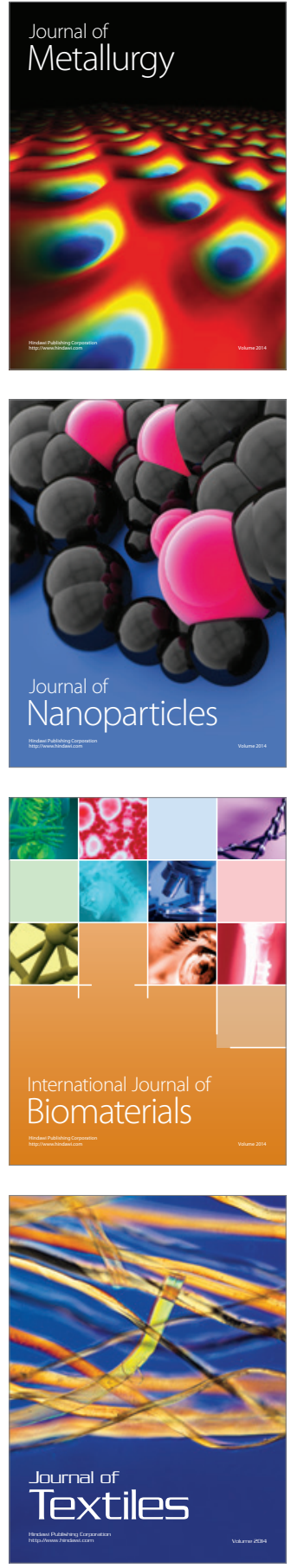